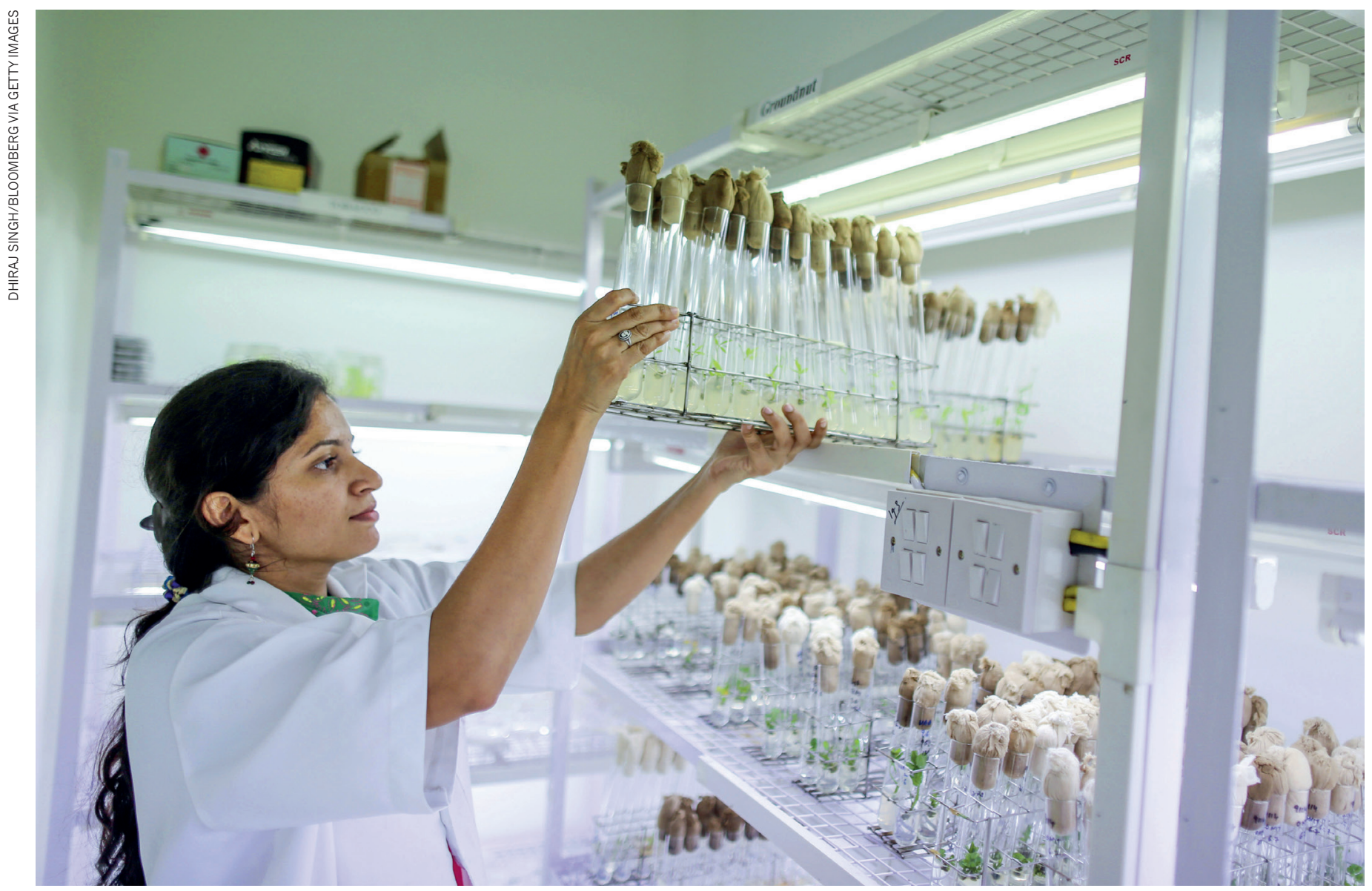

Crop researchers at an institute near Hyderabad, India, are using biotechnology to boost yields of pigeon-pea plants, a food crop and important protein source.

\title{
How Indian biotech is driving innovation
}

\author{
Bolstered by government support, a wealth of investment and an eager \\ graduate workforce, the country's biotechnology industry is booming.
}

\section{BY BIANCA NOGRADY}

\begin{abstract}
$\Lambda$ nu Acharya was in her twenties when the human genome was first mapped in its entirety. In 2000, the young Indian entrepreneur was just breaking into the biotechnology arena with her first start-up - the genomics and bioinformatics company Ocimum Biosolutions in Hyderabad. She saw the Human Genome Project's achievements as opening up a new world of possibilities in personalized medicine, informed by an individual's genetic profile and predispositions but at the time, the field of genomic medicine was dominated by Western science.

"I wanted to make sure that India had its own voice heard in that," Acharya says. So, a decade later, she launched her second biotech start-up - molecular-diagnostics company
\end{abstract}

Mapmygenome, also in Hyderabad - to bring the personalized-medicine revolution to India's diverse population.

"Because, ultimately, when you're making medicine precise, it has to be for specific individuals and populations rather than based on one population that has been studied."

Acharya is among India's rapidly growing ranks of biotechnology entrepreneurs and start-ups that are riding a wave of government enthusiasm, free-flowing venture capital and growing demand from an increasingly wealthy population that wants better treatment options. These factors are helping to drive India's biotechnology industry beyond its historical focus on unbranded generic drugs and into the innovation limelight.
By the end of 2016, there were more than 1,000 biotechnology start-ups in India, and more than half of these had been established within the previous 5 years. Australia, by contrast, has 470 biotechnology companies and the United Kingdom 3,835. The biotechnology industry in India was valued at US\$11 billion in 2016 , and is forecast to grow to $\$ 100$ billion by 2025 .

More than half of the biotechnology start-ups are in the medical arena - diagnostics, drugs and medical devices - but $14 \%$ are in agricultural biotechnology, $3 \%$ in bioindustry, $1 \%$ in bioinformatics and $18 \%$ in biotechnology services.

Biocon in Bangalore is one of them. Now valued at more than $\$ 1$ billion, it started $>$ 
in 1978 as an enzyme manufacturer, but is now making a name for itself in the research and development of biological drugs for treating diabetes, cancer and autoimmune diseases. By March 2018, its revenue had topped $\$ 650$ million.

India has long been a global player in the manufacture of generics (unbranded versions of existing pharmaceutical products), accounting for $20 \%$ of global exports of generics and earning just over $\$ 17$ billion from that market in 2017. So what has prompted the nation to move beyond such a lucrative comfort zone and into the more risky game of biotechnology innovation?

\section{GOVERNMENT SUPPORT}

In 1986, with the encouragement of thenprime minister Rajiv Gandhi, India became one of the first countries in the world to have a government unit dedicated solely to biotechnology. The Department of Biotechnology started with a relatively modest budget of between 40 million and 60 million rupees (\$557,000-835,000), growing exponentially to 24.1 billion rupees in 2018 . In addition to establishing 17 Centres of Excellence in Biotechnology at institutes and universities around the country, the department has supported the creation of 8 biotechnology parks, or incubators, in cities such as Lucknow, Bangalore, Hyderabad, Chennai and Kerala.

The aim of these parks is to provide facilities for scientists and small to medium-sized enterprises (SMEs), where they can develop and demonstrate their technologies and even build pilot plants. The hope is that this will speed up the commercialization process. The park staff also provide mentorship and guidance on issues such as intellectual property, business plans, proposals for clinical development and exit strategies.

This support is helping to address some of the logistical challenges that have hampered industry in the past, says Tej Singh, a biophysicist at the All India Institute of Medical Sciences in New Delhi and president of the Biotech Research Society, India.

"They created some sort of industrial regions in many areas, but there were issues like electricity, water [supply]; all these small things used to take time," Singh says. "But the government has addressed these things nowadays; this current government particularly is very proactive."

The Department of Biotechnology has also supported biotechnology research infrastructure, including a high-resolution mass spectrometry facility in Mumbai, flow-cytometry, imaging and microarray facilities in Delhi, and animal-house facilities in five other regions.

The jewel in the departmental crown, and the scheme that attracts the most attention, is the Biotechnology Industry Research Assistance Council (BIRAC). This is a not-forprofit, public-sector enterprise that was set up by the Department of Biotechnology in 2012

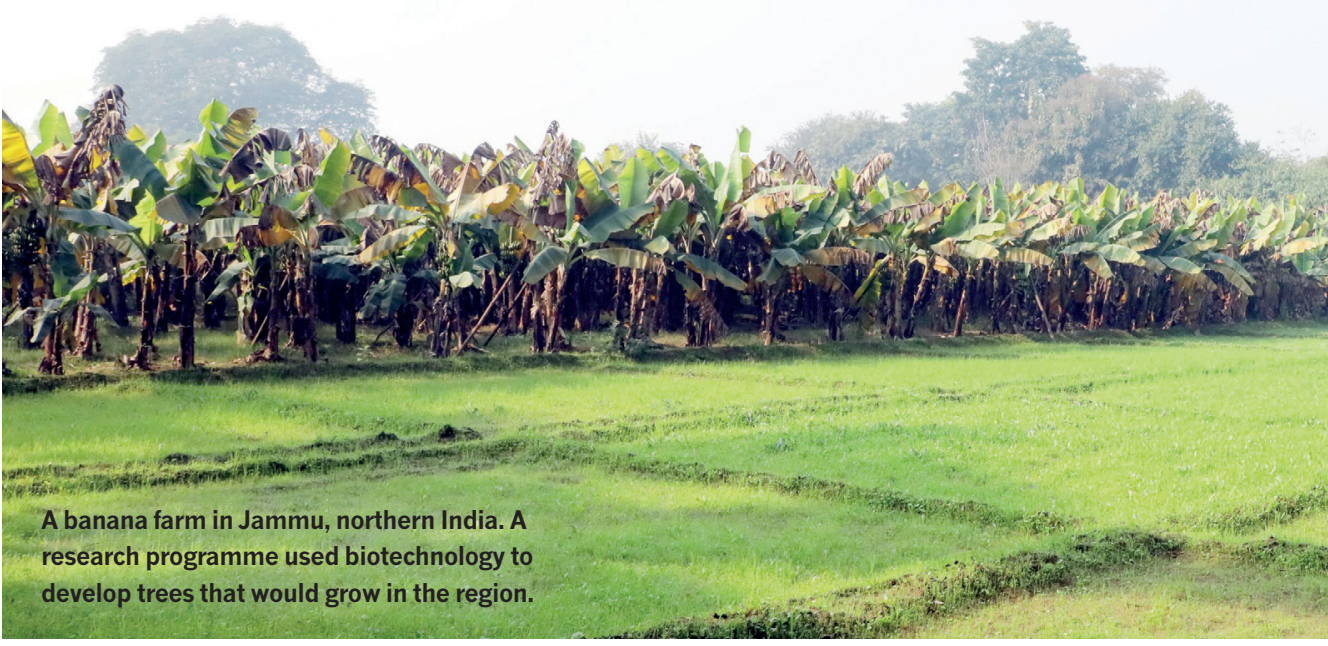

to "stimulate, foster and enhance the strategic research and innovation capabilities of the Indian biotech industry, particularly start-ups and SMEs".

"The idea of forming BIRAC was to support the innovation ecosystem in India, and to nurture innovators from academia and industry to work independently or together," says Shirshendu Mukherjee, mission director of the Program Management Unit at BIRAC. Mukherjee says India has always excelled at basic research but has faced challenges in translating that into commercial outcomes. BIRAC's mission is therefore to "take innovation from the bench to the bedside, from the lab to the field, from the desk to the market", he says.

In just six years of existence, BIRAC has

"A LOT OF
EARLY-STAGE START-
UPS ARE GETTING
BUNDED
BUT I THINK THE
CHALLENGE
IS STILL THE LATE
STAGE."

supported 316 start-ups, which have generated \$125 million through 122 products and technologies, including a cattle-feed supplement, a new process to manufacture human albumin and immunoglobulin, microfluidicsbased diagnostics and a rapid test for malaria.

Its initiatives include 'biotechnology ignition grants' of up to 5 million rupees for start-ups and entrepreneurs to take a proofof-concept through to the first major step on the path to commercialization. Another is a 'glue grants' scheme, which connects clinicalscience departments with those for basic science in institutes and universities in the hope that this will encourage partnerships and collaborations.

BIRAC has also joined forces with the Bill \& Melinda Gates Foundation in Seattle,
Washington, on the Grand Challenges India initiative to tackle global health and development problems.

"I always call my Grand Challenges programme 'in India, for India and beyond"," says Mukherjee. "So we will do it in India, we will validate it in India, we will use it India, our citizens will use it, and then if it goes beyond India we are happy to do that."

\section{CONSUMER DEMAND}

A similar motivation is driving at least some of the scientists and entrepreneurs such as Acharya, who get into the biotech space because they feel that Western biotechnology isn't necessarily addressing the needs of the Indian population. One example is Vivek Wadhwa, a technology entrepreneur at Harvard Law School in Cambridge, Massachusetts, and at Carnegie Mellon University's College of Engineering at Silicon Valley, California, who has invested in Indian medical-diagnostics company HealthCube in New Delhi.

"I did a big study on the pharmaceutical industry in India, and I concluded that Western companies were not addressing Indian disease because it wasn't profitable enough for them," Wadhwa says.

But as the cost of technologies such as genome sequencing and medical sensors comes down, Wadhwa says, it has now become viable for Indian biotechnologists to harness these advances for the Indian market.

And what a market India is for these innovations. The country's population is 1.36 billion and rising, and health care is one of India's fastest-growing sectors, driven by higher incomes and an increasing prevalence of lifestyle diseases, such as heart disease and stroke. By 2022, the health-care market in India is expected to be worth $\$ 372$ billion.

"People are finally realizing that the consumer, or the patient, actually has control over their own health," says Acharya. The rising middle class wants better health and medical choices, and she says that's one of the main drivers for investment in biotechnology research and development.

For example, Biocon has developed the first recombinant insulin to be produced in India, and an antibody-based treatment for head and neck cancer. In 2017, Indian vaccine manufacturer Bharat Biotech in Hyderabad began 


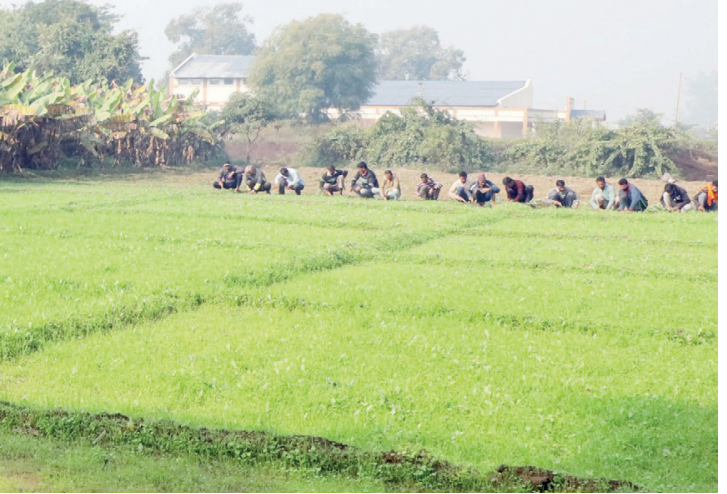

the first clinical trials of its vaccine against the mosquito-borne virus chikungunya, which re-emerged in India in 2006 after 32 years and infected more than 1.4 million people.

Another major driver of the biotechnology boom in India is the accessibility of funding, from both government and private industry. In one 2016 report on biotechnology, India ranked only 49 th out of 54 countries. But it scored particularly highly on the availability of venture capital compared to countries such as the United Kingdom, Australia and Canada (see go.nature.com/2rrpuks).

Acharya says that some of the investors who have made their fortunes in manufacturing generic pharmaceuticals are now investing in biotechnology. She says much of the capital investment in early-stage biotechnology is coming from India, whereas investment in medical devices is flowing from Japan, China and the United States. But late-stage investment is still an issue.

"A lot of early-stage start-ups are getting funded but I think the challenge is still the late stage," she says. "It's not just the first two to three years; it's more how do you take it from start-up to scale-up? I think that's the challenge in terms of getting to where we need to get in terms of biotechnology."

\section{HUMAN RESOURCES}

One thing India has plenty of is people. Recognizing that human capital can be a key resource for a nation not as well endowed financially as Western countries such as the United States or United Kingdom, the Department of Biotechnology implemented or supported various training initiatives. These include the Biotech Industrial Training Programme, set up in 1993 for recent graduates, and 12 Biotech Finishing Schools in Karnataka state to train Indian graduates and researchers in biotechnology.

That programme "created a very large number of institutions or departments of biotechnology in institutions and also departments of bioinformatics", says Singh. For example, in September, the state of Gujarat proposed India's first university focused entirely on biotechnology.

"A decade or so ago, India didn't have the engineers or scientists it does today - it's been graduating them in droves," says Wadhwa. "It has millions of technologists who now just need to be connected to the medical practice and they can be solving great problems."

Singh notes that these graduates aren't waiting for a job to walk up and tap them on the shoulder; they're taking matters into their own hands. "Graduate students who come out in large numbers from Indian institutes of technology and institutes of management are not looking for jobs so much; they create small start-ups and then they grow very fast," Singh says.

Working in biotechnology in India does present its own unique set of challenges, says Acharya. "Some operational things that you never have to think about in the United States you have to plan more in India, because a lot of times we are still importing the reagents and things like that."

\section{RED TAPE}

Although the government of India is enthusiastic about supporting the biotechnology industry, Acharya says the regulatory process for getting products approved could be more streamlined.

In agricultural biotechnology, the government's Genetic Engineering Appraisal Committee has been working to make it easier for companies to get approval for genetically modified crop field trials from state governments.

The drug approvals process in India has hit some rough patches in recent years, and the authors of a 2017 World Health Organization report suggested that innovation there could be outpacing regulation (see go.nature. com/2pkysow). Even the government's own National Biotechnology Development Strategy for 2015-20 acknowledges that timelines and regulatory steps for biotechnology drug approvals are not user-friendly. It has proposed reforms, including the establishment of regulatory departments that are fluent in good practice in the clinical, manufacturing and laboratory arenas.

There are also concerns about the environmental impact of India's pharmaceutical industry. An investigation in 2016 found "unprecedented" levels of pharmaceutical pollution in the water system of Hyderabad (C. Lübbert et al. Infection 45, 479-491; 2017), which is home to a significant proportion of biotech start-ups and generics manufacturers. However, as the US Food and Drug Administration reportedly steps up inspections of overseas pharmaceutical suppliers, environmental standards could be forced to improve.

Despite the challenges, there is palpable excitement about what lies ahead. "Right now, we are seeing the beginnings of a revolution in biotechnology in India," Wadhwa says.

Acharya is still fired with the same enthusiasm that propelled her into biotechnology nearly two decades ago. "Any innovation in this space can actually impact lives," she says. "That's why I continue to be in it." -

Bianca Nogrady is a science writer in Sydney, Australia.

\section{jobs}

\section{INTERVIEWS}

\section{RECRUITMENT}

NEWS

OPINION

INTERACT

\section{CAREERS}

Q\&A

\section{ADVICE}

\section{COMMENT}

\section{UPDATES}

\section{TIPS}

blogs.nature.com/naturejobs 


\section{CORRECTION}

The Spotlight 'How Indian biotech is driving innovation' (Nature 564, S53-S55; 2019) article erred in its description of Biocon as a 'unicorn' start-up. 